\title{
Bir Nakil Merkezinin 11 Yıllık Allojeneik Kök Hücre Nakli Deneyimi
}

\section{Our Approach in Allogeneic Stem Cell Transplantation: 11 Years of Experience}

\author{
Ekin KIRCALI ${ }^{1} \mathbb{D}$, Güldane CENGiz SEVAL ${ }^{1} \mathbb{D}$, Sinem CiVRiz BOZDAĞ ${ }^{1} \mathbb{D}$, \\ Meltem KURT YÜKSEL'1D, Pervin TOPCUOĞLU'D, Önder ARSLAN' ${ }^{1}{ }^{1}$

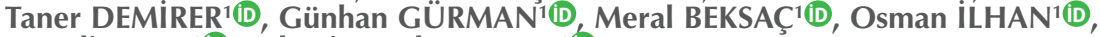 \\ Hamdi AKAN'미, Selami Koçak TOPRAK'1D \\ ${ }^{1}$ Ankara Üniversitesi Tıp Fakültesi, Hematoloji Bilim Dalı, Ankara, Türkiye
}

\section{öz}

Amaç: Allojeneik kök hücre nakli (AKHN), akut lösemiler, kemik iliği yetmezlikleri, myelodisplastik sendromlar, primer refrakter lenfomalar gibi birçok hematolojik hastalıkta küratif bir tedavi seçeneği olmaya devam etmektedir. Ülkemizde de, Dünya'da da yapılma sıklığı artmaktadır. Bugüne kadar 1.4 milyon kök hücre naklinin yapıldığı, yıllık kök hücre nakil sayısının 70.000 civarında olduğu, bunun da yarısının Avrupa' da gerçekleştiği tahmin edilmektedir. Biz de kendi merkezimizdeki allojeneik nakil deneyimimizi, yöntemlerini, endikasyonlarını, sonuçlarını ve mortalite verilerini geriye yönelik olarak araştırmayı hedefledik.

Hastalar ve Yöntem: Çalışmamıza 2010-2020 yılları arasında Ankara Üniversitesi Tıp Fakültesi Hematoloji Bölümü, Nakil Ünitesi'nde allojeneik ve haploidentik kök hücre nakli yapılan tüm hastalar alınmıştır. Hastaların dosyaları ve üniversitenin elektronik sistemi olan Avicenna'daki veriler geriye yönelik olarak taranmıştır.

Bulgular: Hastaların 473'üne (\%91.8) allojeneik, 42'sine (\%8.2) haploidentik nakil yapılmıştır. Toplam 515 hastanın 201'i (\%39) kadındır. Yaş ortancaları 41 (17-71)'dir. Nakil endikasyonları $\operatorname{AML}(s=210, \% 40.8), \operatorname{ALL}(s=91, \% 17.7), \operatorname{MDS}(s=44, \% 8.5), \mathrm{NHL}(s=38, \% 7.4), \mathrm{AA}(s=34, \% 6.6)$, $\operatorname{KMPH}(s=25, \% 4.9), \mathrm{KML}(s=23, \% 4.5), \mathrm{HL}(s=13, \% 2.5)$ ve diğerleridir. Bu çalışmaya göre, 11 yılın sonunda $216(\% 42)$ hasta halen hayattadır. Nükse bağlı mortalite 81 (\%27) hastada, nüks dışı mortalite 218 (\%73) hastada görülmüştür.

Sonuç: Allojenik kök hücre nakli birçok hastalıkta küratif olmakla beraber nüks ve nüks dışı sebeplerle mortalitesi ve komplikasyonları yüksek bir tedavi biçimidir. Ancak uygun verici adaylarının artışı, myeloablatif rejimlerin yanı sıra yoğunluğu azaltılmış hazırlık rejimlerinin getirilmesi, kök hücre nakli için uygun görülen yaş aralığının genişlemesi, nakil sonuçlarının giderek iyileşmesini sağlamaktadır.

Anahtar Kelimeler: Allojeneik kök hücre nakli; Haploidentik kök hücre nakli; Transplant deneyimi

\section{ABSTRACT}

Objective: Allogeneic hematopoietic cell transplant has been a curative choice of treatment for a diverse scale of benign and malignant diseases such as acute leukemias, bone marrow failure and myelodysplastic syndromes, primary refractory lymphomas etc. It has been more and more utilized both in Turkey and in the world. It is estimated that a total of 1.4 million hematopoietic cell transplantations have been performed worldwide and 70.000 transplantations are being performed annually, half of which occurs in Europe. Here, we aimed to retrospectively analyze our center's allotransplant experience, methods, indications, results and mortality data.

Patients and Methods: All the patients who underwent allogeneic and haploidentic hematopoietic cell transplantation in Ankara University, Faculty of Medicine Hematology Department, transplantation unit between 2010-2020 were included in our study. The patient files and the data from Avicenna -the electronic record system of the university- were scanned retrospectively. 
Results: 473 (91.8\%) of patients received allogeneic, 42 (8.2\%) received haploidentical transplants. 201 (39\%) of a total of 515 patients are women, median age of whom is 41 (17-71) years. Main transplant indications were as follows: AML $(n=210,40.8 \%), A L L(n=91,17.7 \%)$, $\operatorname{MDS}(n=44,8.5 \%), \mathrm{NHL}(n=38,7.4 \%), \mathrm{AA}(n=34,6.6 \%), \mathrm{KMPH}(n=25,4.9 \%), \mathrm{CML}(n=23,4.5 \%), \mathrm{HL}(n=13,2.5 \%)$ and others. According to the present study, 216 (42\%) patients are currently alive. Relapse related mortality occurred in 81 (27\%), non-relapse mortality was observed in 218 (73\%) patients.

Conclusion: Although allogeneic hematopoietic cell transplantation is curative in many diseases, it is a treatment method with high complications and mortality due to relapse and non- relapse conditions. However the increase in suitable donor candidates, the introduction of non- myeloablative, reduced intensity conditioning regimens and the widening of the age range deemed appropriate for stem cell transplantation provide gradual improvement in transplant results with time.

Key Words: Allogeneic hematopoietic cell transplant; Haploidentic hematopoietic cell transplant; Transplantation experience

\section{Giriş}

Allojeneik hematopoetik kök hücre nakli (AHKHN); akut lösemiler, kemik iliği yetmezlikleri, myelodisplastik sendromlar, primer refrakter lenfomalar gibi birçok hematolojik hastalıkta küratif bir tedavi seçeneği olarak tercih edilmeye devam etmektedir. Bugüne kadar 1.4 milyon otolog ve allojeneik kök hücre naklinin yapıldığı, yıllık kök hücre nakil sayısının 70.000 civarında olduğu, bunun da yarısının Avrupa'da gerçekleştiği tahmin edilmektedir (1). European Society for Blood and Marrow Transplantation (EBMT) verilerine göre 2018'de EBMT üyesi toplam 50 ülkeden, 701 nakil merkezinde 42.901 hastaya 47.468 kök hücre nakli yapılmıştır. Bunların 19.630'u (\%41) allojeneik nakil olmuştur (2).

Yıllar içinde, hematopoetik hücre naklinde düşük yoğunluklu hazırlık rejimlerinin devreye girmesi, doku gruplarının daha yüksek çözünürlüklü tiplendirmeyle daha uyumlu vericilerin bulunur hale gelmesi, nakil ilişkili enfeksiyonların daha iyi yönetilmeye başlanması, graft versus host hastalığına $(\mathrm{GvHH})$ dair koruyucu ve tedavi edici yaklaşımların iyileşmesiyle büyük yol kat edilmiştir. Bununla birlikte, nakil ilişkili trombotik mikroanjiopatiden $\mathrm{GvHH}^{\prime} y e$, kanamlardan malnutrisyona, böbrek hasarından akciğer sorunlarına komplikasyonlara da sebep olabilen, mortalite potansiyeli taşıyan bir tedavi rejimidir. Biz de kendi merkezimizdeki allojeneik nakil deneyimimizi, yöntemlerini, endikasyonlarını, sonuçlarını ve mortalite verilerini geriye dönük olarak araştırmayı hedefledik.

\section{HASTALAR ve YÖNTEM}

Çalışmamıza, 2010- 2020 yılları arasında merkezimizde AHKHN ve haploidentik kök hücre nakli (haplo-KHN) yapılan hastalar dahil edilmiştir. Hastaların verileri, hasta dosyaları ve üniversitenin elektronik kayıt sisteminden geriye dönük olarak incelenmiştir. Hastaların tanıları, tanı yaşları, hazırlık rejimleri, kök hücre kaynakları, GvHH verileri, nakil öncesi ve sonrası hastalık durumları değerlendirmeye alınmıştır.

\section{BULGULAR}

Çalışmaya dahil edilen hasta sayısı 515 olup bu hastaların \%39'u ( $s=201)$ kadın cinsiyetti. Hasta grubunun ortan- ca yaşı 41 yıl (aralık: 17-71 yıl) olarak hesaplandı. Hastalara en sık akut myeloblastik lösemi $(\% 40,8(s=210))$ ve akut lenfoblastik lösemi (ALL) (\%17.7 ( $(s=91))$ nedeniyle nakil yapılmıştır. Hastaların diğer demografik özellikleri Tablo 1'de özetlenmiştir.

Hastaların 473'üne (\%91.8) allojeneik, 42'sine (\%8.2) haploidentik nakil yapılmıştır. Çalışmaya dahil edilen hastaların çoğunluğunda (\%86.6) kök hücre kaynağı olarak çevre kanı kullanılmıştır. Kök hücre nakli öncesi hastaların çoğunluğunun ( $s=147, \% 28.5$ ) birinci tam remisyonda olduğu görüldü. Bunu sırasıyla aktif hastalık ( $s=115, \% 22.4$ ) ve ikinci tam remisyon ( $s=52, \% 10.1$ ), takip etmektedir. Nakil öncesi kullanılan başlıca hazırlık rejimleri; BuCy ( $s=115$, $\% 22.3)$, CyTBI ( $s=109, \% 21.2)$, FluBu ( $s=52, \% 10.1)$, CyBu $(s=46, \% 8.9)$, FluCyTBI $(s=31, \% 6)$, FluMel $(s=23, \% 4.5)$, TBF $(s=18, \% 3.5)$ olmuştur. Nakil sonrasında $183(\% 35.5)$ hastada CMV reaktivasyonu gözlenmiştir. Çalışmaya dahil edilen hastaların ortanca nötrofil ve trombosit engraftmanları SIrasıyla +16 . günde $v e+13$. günde gerçekleşmiş̧ir.

Nakil sonrası takiplerinde; 177 hastada akut GvHH geliştiği görüldü, akut GvHH gelişen hastaların \%42'sinde birden fazla organ tutulumu olduğu görüldü. Sık tutulan organlar sırasıyla gastrointestinal sistem (GIS) ( $s=99)$, cilt ( $s=$ $84)$ ve karaciğerdi $(s=33)$. Hastaların \%20.6'sında $(s=106)$ kronik GvHH 106 (\%20.6) geliştiği görüldü. Bu hastalardaki organ tutulumları sırasıyla; 59 hastada cilt, 61 hastada GIS, 67 hastada karaciğerdi, 21 hastada da göz tutulumu görüldü. Nakil sonuçları Tablo 3' te kısaca özetlenmiştir.

Verilerin değerlendirme tarihinde hastaların 216'sı (\%42) yaşamaktaydı. Hastaların başlıca ölüm nedenleri; hastalık nüksü ( $s=81, \% 27)$, sepsis/ağır enfeksiyon ( $(s=67, \% 13)$, $\mathrm{GvHH}(\mathrm{s}=34, \% 6.6)$, sinüzoidal obstrüksiyon sendromu ( $s=$ $11, \% 2.1)$, kardiyak olay/akut koroner sendrom $(s=5, \% 1)$ ve diğer sebeplerdir (engraftman yetmezliği, intrakranyal kanama, radyasyon pnömonisi, suisid, hemorajik sistit, ağır astım atağı vd.). Çalışmaya dahil edilen hastaların nakil sonrası nüks dışı mortalite oranı \%77.5 olarak hesaplanmıştır. Hastaların nakil ilişkili ölüm oranı ise \%29.3'tür ( $s=149$ ).

Allojeneik kök hücre naklinden sonra ikincil kanserler de daha fazla görülmektedir. Bunlar solid organ kanser- 
Tablo 1. Demografik özellikler

\begin{tabular}{ll}
\hline Kadın: Erkek & $201: 314(\% 39: \% 61)$ \\
Ortanca yaş (yıl) & $41(17-71)$ \\
Tanılar & $210(\% 40.7)$ \\
AML & $91(\% 17.6)$ \\
ALL & $44(\% 8.5)$ \\
MDS & $38(\% 7.4)$ \\
NHL & $34(\% 6.6)$ \\
AA & $25(\% 4.9)$ \\
KMPH & $23(\% 4.5)$ \\
KML & $13(\% 2.5)$ \\
HL & $7(\% 1.4)$ \\
PHD & $6(\% 1.2)$ \\
KLL & $24(\% 4.7)$ \\
Diğer (immün yetmezlikler, PNH vs.) & $14.9(1-487)$ \\
Tanıdan nakile kadar geçen ortanca süre (ay) & \\
Nakil türü & $473(\% 91.8)$ \\
Allojeneik & $42(\% 8.2)$ \\
Haploidentik & \\
\hline
\end{tabular}

\section{Tablo 2. Genel özellikler}

\begin{tabular}{ll} 
Verici türü & \\
$\quad$ Akraba verici & $287(\% 55.7)$ \\
Akraba dışı verici & $228(\% 44.3)$ \\
HLA uyumu & \\
$10 / 10$ & $345(\% 67)$ \\
$9 / 10$ & $120(\% 23.3)$ \\
$\geq 2$ mismatch & $50(\% 9.7)$ \\
Hazırlık rejimi & \\
Miyeloablatif & $370(\% 71.8)$ \\
Indirgenmiş yoğunluklu & $143(\% 27.8)$ \\
Diğer & $2(\% 0.4)$ \\
GvHH proflaksisi & \\
CsA+MMF & $99(\% 19.2)$ \\
CsA+Mtx & $358(\% 69.5)$ \\
Takrolimus+MMF & $17(\% 3.3)$ \\
Takrolimus+Mtx & $8(\% 1.5)$ \\
CsA & $8(\% 1.5)$ \\
Diğer & $25(\% 5)$ \\
\hline
\end{tabular}

CsA: Siklosporin-A, Mtx: Metotreksat, MMF: Mikofenolat mofetil.

leri olabildiği gibi hematolojik maligniteler de olabilir (6). Bizim hasta grubumuzda da 1 hastada sekonder AML, 1 hastada dil adenokanseri, 1 hastada over germinal tümör, 1 hastada Kaposi sarkomu, 2 hastada kolorektal kanser görülmüştür. 21 hastada (\%0.04) göz tutulumu olan kronik GvHH geliştiği görülmüştür. 2 hasta, EBV ilişkili nakil sonrası lenfoproliferatif hastalık nedeniyle kaybedilmişlerdir. Bir diğer önemli nakil komplikasyonu ise kronik böbrek hastalığı ve buna bağlı gelişen nefrotik sendromdur (8). Bizim çalışmamızda 2 hastada nakil sonrası nefrotik sendrom geliştiği görülmüştür ve bu hastalar yüksek doz siklofosfamide yanıtsız olup kaybedilmişlerdir.

\section{TARTIŞMA ve SONUÇ}

AHKHN hematolojik hastalıklarda hala günümüzde tek küratif tedavi yöntemlerinden biri olmaya devam etmektedir. Bununla birlikte, kök hücre naklinden sonra beklenen tahmini ömür, genel topluma kıyasla 10-20 yıl daha kısadır (3). Nakilden sonraki ilk yıllarda en büyük ölüm riski, nakil nedeni olan hastalığın nüks etmesidir. Wingard ve arkadaşları yapmış olduğu ve 10.000 'den fazla hastanın dahil edildiği bir çalışmada; akut lösemi, myelodisplastik sendrom, lenfoma ya da ciddi aplastik anemi tanılarıyla myeloablatif hazırlık rejimi kullanılarak AHKHN yapılan ve 2 yıl süreyle hastalık kontrolü sağlanan hastalarda 10 yıllık sağ kalım oranı \%85 olarak bildirilmiştir (3). 


\section{Tablo 3. Nakil sonuçları ve GvHH}

$\begin{array}{ll}\text { Hastaların nakil yanıtları } & \\ \text { Tam remisyon } & 274(\% 53.2) \\ \text { Aktif hastalık } & 56(\% 10.9) \\ \text { Kısmi remisyon } & 23(\% 4.5) \\ \text { Nakil başarısızlığı } & 15(\% 2.9) \\ \text { Diğer } & 147(\% 28.5) \\ \text { aGvHH } & \mathrm{s}=177(\% 34.4) \\ \text { Cilt } & \mathrm{s}=84(\% 16.3) \\ \text { Gastrointestinal sistem } & \mathrm{s}=67(\% 13) \\ \text { Karaciğer } & \mathrm{s}=19(\% 3.6) \\ \text { kGvHH } & \mathrm{s}=106(\% 20.6) \\ \text { Cilt } & \mathrm{s}=59(\% 11.5) \\ \text { Gastrointestinal sistem ve oral mukoza } & \mathrm{s}=61(\% 11.9) \\ \text { Karaciğer } & \mathrm{s}=67(\% 13) \\ \text { Göz } & \mathrm{s}=21(\% 4) \\ \text { Akciğer (BOOP) } & \mathrm{s}=7(\% 1.3)\end{array}$

GvHH: Graft vs host hastalığı, BOOP: Bronşiolitis obliterans obstrüktif pnömoni.

Tek merkezden 1500'e yakın hastanın dahil edildiği bir başka çalışmada ise AKHN yapıldıktan sonra $\geq 2$ yıl yaşayan hastalarda 15 yıllık sağ kalımın \%80 olduğu bildirilmiştir. Bizim çalışmamızda da literatürdeki gibi, nakil sonrası nüks mortalitenin en önemli sebeplerinden biri olmuştur. Erken dönemde ölümün en sık sebebi (\%29) nakil nedeni olan hastalığın nüksü olmuştur (4). Nüks özellikle, nakil sonrası ilk 4 yılda ölümün en sık nedeni olup, nakil sonrası ilk 4 yılda nüks gelişmeyen hastalarda uzun dönem sağ kalım beklentisi yüksektir (5). Bizim çalışmamıza alınan hasta grubunda da nükse bağlı ölüm \%27 oranında görülmüştür. Nüks dışı mortalitenin önde gelen sebepleri de $\mathrm{GvHH}$, enfeksiyonlar ve sepsis, ikincil kanserler ve organlarda işlev bozukluklarının olduğu görülmüştür.

Gözle ilişkili nakil komplikasyonları kronik göz kuruluğu (keratokonjunktivitis sikka), katarakt, üveit, koroidit, retinit ve retinal mikrodamar hastalığı olarak sayılabilir. Hazırlık rejiminde tüm vücut ışınlama (TVI) alan hemen tüm hastalarda katarakt gelişebilir (9). Keratokonjunktivitis sikka da hem TVI'dan hem de kronik GvHH'den kaynaklanabilir. Özellikle kronik GvHH hastalarında \%40 kadar yüksek olabileceği literatürde belirtilmiştir $(10,11)$. Hastaların AKHN' nin birinci yılında, nakil komplikasyonlarına hakim bir göz uzmanı tarafından katarakt, kuru göz, iskemik vasküler retinopati açılarından değerlendirilmesi, görüş keskinliği ve fundus muayenelerinin yapılması gereklidir $(11,12)$. Bizim çalışmamızda da 21 hastada kronik GvHH görülmüştür (Tablo 3).

Hematopoetik kök hücre nakli benign ve malign hematolojik bozuklukları tamamen tedavi edebilir ancak bütün gelişmelere rağmen uzun dönem komplikasyonlar nedeniyle hastaların hayatı kısıtlanabilmektedir. AKHN yapılmış olan hastalar nakil ilişkili komplikasyonlar açısın- dan gözlenmeli, bunlar mümkünse engellenmeli, engellenemiyorsa en iyi şekilde, multidisipliner bir yaklaşım ile yönetilmelidir. Sonuç olarak uygun verici adaylarının artışı, myeloablatif rejimlerin yanı sıra yoğunluğu azaltılmış hazırlık rejimlerinin geliştirilmesi, kök hücre nakli için uygun görülen yaş aralığının genişlemesi, nakil sonuçlarının giderek iyileşmesini sağlamaktadır.

\section{ETIK KURUL ONAYI}

Çalışma için Ankara Üniversitesi Tıp Fakültesi Etik Kurulu'ndan onay alındı. (Karar no: i8-543-20 Tarih: 07.09.2020).

\section{ÇIKAR ÇATIŞMASI}

Yazarların çıkar çatışması bulunmamaktadır.

\section{MALI AÇIKLAMA}

Çalışma için doğrudan ya da dolaylı mali destek alınmamıştır. Çalışmanın herhangi bir firma ya da kişiyle ticari bağlantısı yoktur.

\section{YAZAR KATKISI}

Literatür taranması: EK; Verilerin Toplanması: EK; Makalenin Yazımı: EK, GCS; Onaylama: Tüm yazarlar.

\section{KAYNAKLAR}

1. Gratwohl A, Paquini MC, Aljurf M, Atsuta $Y$, Baldomero H, Foeken $L$, et al. One million haemopoietic stem-cell transplants: a retrospective observational study. The Lancet Haematol. 2015;3:e91-e100.

2. European Group for Blood and Marrow Transplantation. Available from: https://www.ebmt.org/sites/default/files/2020-04/ EBMT-Annual-Report-2019.pdf. 2019.

3. Wingard JR, Majhail NS, Brazauskas R, Wang Z, Sobocinski KA, Jacobsohn $D$, et al. Long-term survival and late deaths after allogeneic hematopoietic cell transplantation. J Clin Oncol. 2011;29:2230 
4. Bhatia S, Francisco L, Carter A, Sun CL, Baker KS, Gurney JG, et al. Late mortality after allogeneic hematopoietic cell transplantation and functional status of long-term survivors: report from the Bone Marrow Transplant Survivor Study. Blood, 2007;110:3784-92.

5. Majhail NS. Long-term complications after hematopoietic cell transplantation. Hematol Oncol Stem Cell Ther. 2017;10:220-27.

6. Rizzo JD, Curtis RE, Socie G, Sobocinski KA, Gilbert E, Landgren O, et al. Solid cancers after allogeneic hematopoietic cell transplantation. Blood. 2009;113:1175-83.

7. Straathof KC, Savoldo B, Heslop HE, Rooney CM. Immunotherapy for post-transplant lymphoproliferative disease. $\mathrm{Br} J$ Haematol. 2002;118:728-40.

8. Ando M, Ohashi K, Akiyama H, Sakamaki H, Morito T, Tsuchiya $\mathrm{K}$, et al. Chronic kidney disease in long-term survivors of myeloablative allogeneic haematopoietic cell transplantation: prevalence and risk factors. Nephrol Dial Transplant. 2010;25:278-82.

9. Majhail NS, Ness KK, Burns LJ, Sun CL, Carter A, Francisco L, et al. Late effects in survivors of Hodgkin and non-Hodgkin lymphoma treated with autologous hematopoietic cell transplantation: a report from the bone marrow transplant survivor study. Biol Blood Marrow Transplant. 2007;13:1153-9.
10. Rizzo JD, Wingard JR, Tichelli A, Lee SJ, Lint MTV, Burns LJ, et al. Recommended screening and preventive practices for longterm survivors after hematopoietic cell transplantation: joint recommendations of the European Group for Blood and Marrow Transplantation, the Center for International Blood and Marrow Transplant Research, and the American Society of Blood and Marrow Transplantation. Biol Blood Marrow Transplant. 2006;12:138-51.

11. Majhail NS, Rizzo JD, Lee SJ, Aljurf M, Atsuta Y, Bonfime C, et al. Recommended screening and preventive practices for longterm survivors after hematopoietic cell transplantation. Hematol Oncol Stem Cell Ther. 2012;5:1-30.

12. Inamoto Y, Petricek I, Burns L, Chhabra S, DeFilipp Z, Hematti P, et al. Non-graft-versus-host disease ocular complications after hematopoietic cell transplantation: expert review from the Late Effects and Quality of Life Working Committee of the Center for International Blood and Marrow Transplant Research and the Transplant Complications Working Party of the European Society for Blood and Marrow Transplantation. Biol Blood Marrow Transplant. 2019;25:e145-e54. 